\title{
Caffeine Inhibits Migration in Glioma Cells through the ROCK-FAK Pathway
}

\author{
Ying Chen ${ }^{\mathrm{a}}$ Wei-Chung Chou ${ }^{\mathrm{a}}$ You-Ming Ding ${ }^{\mathrm{a}}$ Ya-Chieh Wu \\ aDepartment of Biology and Anatomy, National Defense Medical Center, Taipei, bepartment of \\ Nursing, Ching Kuo Institute of Management and Health, Keelung, Taiwan
}

\section{Key Words}

Caffeine $\cdot$ Rho associated kinase $\cdot$ Focal adhesion kinase $•$ Glioma

\begin{abstract}
Aims: Glioma is the most malignant brain tumor that has the ability to migrate and invade the CNS. In this study, we investigated the signaling mechanism of caffeine on the migration of glioma cells. Methods: The effect of caffeine on cell migration was evaluated using Transwell and wound healing assays. The expression of the focal adhesion complex as it related to cell migration was assayed using Western blotting and immunostaining. Results: Caffeine decreased the migration of rat C6 and human U87MG glioma cells and down-regulated the expression of phosphorylated focal adhesion kinase ( $p$-FAK) and p-paxillin. Caffeine also decreased $p$-FAK staining at the edge of glioma cells and disassembled actin stress fibers. Additionally, caffeine elevated expression of phosphorylated myosin light chain ( $p-M L C)$, an effect that could be blocked by Y27632, a rho-associated protein kinase (ROCK) inhibitor, but not myosin light chain kinase inhibitor, ML-7. Y27632 also inhibited the caffeine-reduced expression of p-FAK and p-paxillin as well as cell migration. Conclusion: Caffeine decreased the migration of glioma cell through the ROCK-focal adhesion complex pathway; this mechanism may be useful as part of clinical therapy in the future.
\end{abstract}

Copyright $\odot 2014$ S. Karger AG, Basel

\section{Introduction}

Gliomas are common malignant brain tumors derived from glia cells in the central nervous system. Glioma invasion into other brain tissue makes the disease difficult to treat, and despite surgery and chemotherapy, the mean survival rate for glioma patients is usually less than a year [1]. According to the World Health Organization, gliomas can be classified 
into the following three groups, based on the differentiation of astrocytomas: diffuse astrocytoma, anaplastic astrocytoma, and undifferentiated glioblastoma multiform (GBM) [2]. It is important to determine therapeutic solutions that may work in combination with the traditionally clinical therapy for treating gliomas.

Coffee, tea, or caffeine-containing beverages have been reported to reduce the risk of gliomas in adults [3]. Caffeine can penetrate the blood-brain barrier, which normally restricts chemotherapeutic agents or drugs [4]. By increasing phosphorylation of p21 and glycogen synthase kinase 3 beta (GSK-3 $\beta$ ), caffeine reduces the proliferation of human U87MG glioma cells both in vitro and in subcutaneous xenograft models [5]. Moreover, caffeine increases ionizing radiation-induced G1 arrest in several human glioblastoma cells [6]. igh concentrations of caffeine reduce migration and invasion in vitro and in brain slices through inositol-1, 4, 5-triphosphate receptor (IP3R)-calcium cascades in human glioblastoma cells [7]. Unfortunately, the mechanism by which caffeine reduces glioblastoma cell migration and invasion remains unclear.

Adhesion, migration, and invasion are important for glioma cell metastasis. The focal adhesion complex is responsible for cell adhesion to the extracellular matrix (ECM) through integrin [8]. The activity of integrin $\beta 1$ and focal adhesion kinase (FAK) are both related to the formation of the focal adhesion complex, which controls cell adhesion and migration in human glioblastoma [9]. Moreover, the expression of FAK, a protein kinase involved in the focal adhesion complex, is elevated in human anaplastic astrocytoma and glioblastoma [10]. Down-regulation of integrin- $\alpha v \beta 3$, which adheres to fibronectin, decreases the migration of human glioblastoma cells [11]. Furthermore, rho-associated protein kinase $(R O C K)$ and myosin light chain kinase (MLCK) both contribute to the phosphorylated myosin light chain (MLC), decreasing the turnover of focal complexes and cell migration in fibroblasts [12]. In human glioblastoma cells, ROCK activation decreases cell migration and impairs the balance of F- and G-actin [13]. The focal adhesion complex may be a potential treatment target for glioblastoma.

The aim of this study was to determine the effects of caffeine on cell migration and the underlining mechanisms for these effects in glioma cells. This research suggests that the ROCK-FAK cascade plays an important role in the effect of caffeine in glioma cells.

\section{Materials and Methods}

\section{Cell culture}

Rat C6 and human U87MG glioblastoma cell lines were purchased from the American Type Culture Collection (Rockville, MD). The cells were grown in Dulbecco's Modified Eagle's Medium (DMEM) containing $10 \%$ fetal bovine serum and $100 \mathrm{IU} / \mathrm{ml}$ penicillin and streptomycin (pH 7.4) (all obtained from Gibco BRL, Grand Island, NY) in a humidified atmosphere of $5 \% \mathrm{CO}_{2}$ at $37^{\circ} \mathrm{C}$.

Drugs

The 4', 6-diamidino-2-phenylindole dilactate (DAPI) and 2.3.3-[4, 5-dimethylthiazol-2-yl]-2, 5-diphenyltetrazolium bromide (MTT) used in this study were obtained from Sigma-Aldrich (St. Louis, MO). Caffeine was purchased from TOCRIS (TOCRIS Cookson Inc., Bristol, UK). Y27632 and ML-7 were obtained from Enzo Life Sciences (Plymouth Meeting, PA).

\section{Cell survival assay}

C6 and U87MG glioblastoma cells were plated at $2 \times 10^{4}$ cells per well in a 24-well plate. Different concentrations of caffeine or vehicle control $\mathrm{H}_{2} \mathrm{O}$ were then added to the culture medium for $24 \mathrm{~h}$. After the cells were washed with phosphate-buffered saline (PBS) (137 mM NaCl, $2.7 \mathrm{mM} \mathrm{KCl}, 1.5 \mathrm{mM} \mathrm{KH}_{2} \mathrm{PO}_{4}, 8 \mathrm{mM}$ $\mathrm{Na}_{2} \mathrm{HPO}_{4}$, and $\mathrm{pH} 7.4$ ), $500 \mu \mathrm{l}$ of DMEM containing $0.5 \mathrm{mg} / \mathrm{ml}$ of MTT was added and incubation continued for another $4 \mathrm{~h}$. The cells were then lysed with $500 \mu \mathrm{l}$ of DMSO. Absorbance at $590 \mathrm{~nm}$ was measured. 


\section{Migration assay}

Cell migration was assayed using Transwell and wound healing assays. The Transwell migration assay was prepared by seeding $5 \times 10^{4}$ C6 or U87MG glioma cells in the upper chamber of a Transwell (Costar, Acton, MA, USA). After cell attachment, growth medium either with or without caffeine was added for 24 $\mathrm{h}$. The cells on the lower side were fixed in 10\% formalin and stained with Coomassie Brilliant Blue G250 (Sigma, St. Louis, M0). The number of migrated cells was counted in three randomly selected fields from each membrane, with the membranes examined three times in each experiment group. The wound healing assay was prepared by growing cells to confluence to form a monolayer. The cells were then scratched using a P200 pipette tip and photographed as previously described [14]. After $24 \mathrm{~h}$ of treatment with caffeine, wound healing was photographed again. Images are representative of three different experiments.

\section{Adhesion assay}

After being treated with either caffeine or $\mathrm{H}_{2} \mathrm{O}$ for $24 \mathrm{~h}$, the U87MG glioma cells were suspended and then plated on fibronectin-coated or non-coated dishes as described previously [15]. Cells were left to adhere for $15 \mathrm{~min}$, after which the medium and non-adhered cells were discarded. After being washed with PBS, the adhered cells were examined by microscope and counted per field.

\section{Western blotting}

After the various treatments, the C6 or U87MG glioma cells were washed once with PBS and then homogenized in lysis buffer (10 mM EGTA, 2 mM MgCl, 60 mM PIPES, 25 mM HEPES, 0.15\% Triton X-100, $1 \mu \mathrm{g} / \mathrm{ml}$ of pepstatin A, $1 \mu \mathrm{g} / \mathrm{ml}$ of leupeptin, $1 \mathrm{mM} \mathrm{NaF}$, and $1 \mathrm{mM}$ phenylmethylsulfonyl fluoride). Protein samples (60 $\mu \mathrm{g}$ per lane) were electrophoresed on a 10\% SDS polyacrylamide gel and transferred to a nitrocellulose membrane (Bio-Rad Life Science). Strips from the membrane were blocked with $5 \%$ non-fat milk in Tris-buffered saline, pH 8.2, containing 0.1\% Tween (TBS-Tween) and incubated overnight at $4 \stackrel{\circ}{\circ} \mathrm{C}$ with a 1:500 dilution of rabbit antibodies against phosphorylated FAK (p-FAK), phosphorylated paxillin (p-paxillin), GAPDH (BioVision Research Products, Mountain View, CA), phosphorylated MLC (p-MLC), MLC, and ROCK (Cell Signaling) or mouse antibody against $\beta$-actin (Sigma-Aldrich), integrin $\beta 1$, FAK, and paxillin (BD Biosciences Pharmingen, San Diego, CA). After the washings, the strips were incubated with a 1:7500 dilution of alkaline phosphatase-conjugated anti-mouse or anti-rabbit IgG antibodies (Promega Corp., Madison, WI). Peroxidase-conjugated secondary antibody was used for chemiluminescence detection. After buffer wash, the blots were reacted in ECL substrate developing solution (Millipore). The density of the bands on the nitrocellulose membrane was quantified by densitometry using Gel Pro 3.1 (Media Cybernetics, Silver Spring, MD), taking density of the control sample as $100 \%$ and expressing density of the test sample relative to the expression of internal control as a relative value. Phosphorylated proteins were normalized to the total protein first.

\section{Immunocytochemistry}

After caffeine treatment, the cells were rinsed with PBS and fixed with $10 \%$ formalin. Primary antibody dissolved in PBS with blocking solution (5\% non-fat milk in $0.1 \%$ Triton X-100) was added at $4{ }^{\circ} \mathrm{C}$ overnight. After rinsing with PBS, FITC-conjugated goat anti-mouse IgG antibodies (Jackson ImmunoResearch Laboratories, Inc. West Grove, PA) were introduced. Stress fibers were stained using TRITC-conjugated-phalloidin (Sigma), while DAPI was counterstained to observe the nucleus. Eventually, the cells were mounted with mounting medium (Gel mount Aqueous, Sigma), observed using a fluorescent microscope (DM2500, Leica, Germany), and recorded with a Nikon D1X digital camera (Luca-R, Andor, Northern Ireland).

\section{Statistical analysis}

All experiments were performed at least three times and the results were expressed as the mean \pm SEM for the total number of experiments. Significant differences between means were assessed using the Kruskal-Wallis test. The Mann-Whitney test was used for post analysis. Statistical significance was set at $p<0.05$. 
Fig. 1. The effect of caffeine on cell viability and migration. (A) Human U87MG glioma cells and (B) rat C6 glioma cells were treated with $\mathrm{H}_{2} \mathrm{O}$ or different concentrations of caffeine for 24 hours. After treatment, the survival rate was analyzed using MTT tests. Values are expressed relative to the control group. ${ }^{*} p<0.05$; ${ }^{* *} p<0.01$ compared to the control group. (C) Rat C6 and human U87MG glioma cells were seeded in the upper chamber of a Transwell. After 24 hours of incubation with or without caffeine, the number of cells in the lower chamber was calculated. (D) Rat C6 and U87MG glioma cell monolayers were scratched and incubated with or without $0.5 \mathrm{mM}$ caffeine for $24 \mathrm{~h}$ treatment. The wound area was analyzed using ImageJ software and expressed relative to 0 hours. ${ }^{*} p<0.05 ;{ }^{* *} p<0.01$ compared to the control group in $24 \mathrm{~h}$.

\section{Results}

Caffeine reduced cell migration in glioma cells

The effect of caffeine on the survival rate of glioma cells was first tested using MTT assays. The cell viability of human U87MG and rat C6 glioma cells was unaffected when the cells were given doses of caffeine under $0.5 \mathrm{mM}$ (Figs. $1 \mathrm{~A}$ and $1 \mathrm{~B}$ ). Caffeine at $1 \mathrm{mM}$ reduced

B

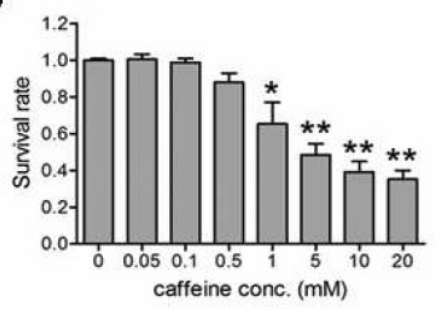

Caf $0.5 \mathrm{mM}$

Caf $1 \mathrm{mM}$

C

D

C6

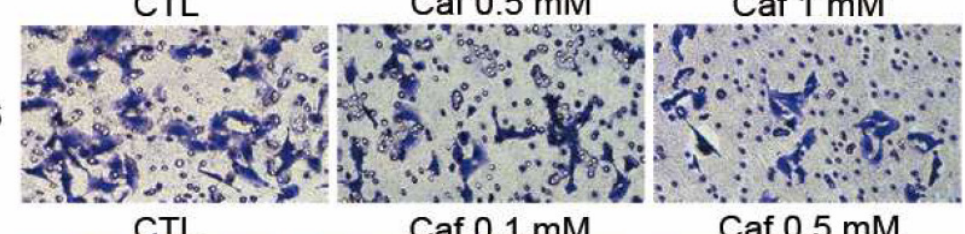

U87MG

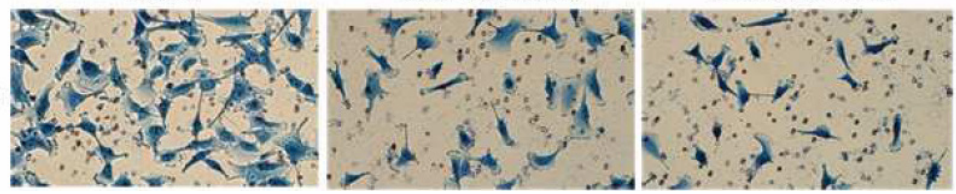

$\mathrm{Oh}$

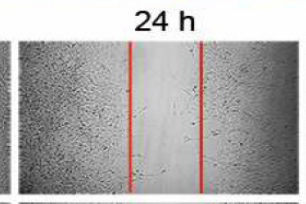

$48 \mathrm{~h}$

U87MG
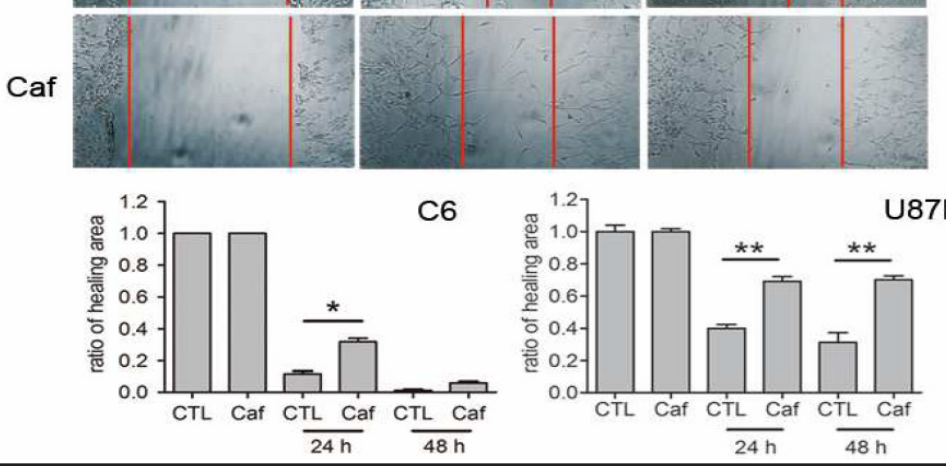

U87MG 
Fig. 2. Caffeine reduced activity of the focal adhesion complex. (A) C6 glioma cells were treated for the indicated time with $\mathrm{H}_{2} \mathrm{O}$ or $0.5 \mathrm{mM}$ c a f f e in e. Cell lysates were then analyzed for integrin $\beta 1$, FAK, p-FAK, paxillin, and p-paxillin using western blotting of C6. (B) U87MG glioma cells were treated with $\mathrm{H}_{2} \mathrm{O}$ or 0.5 mM caffeine for $24 \mathrm{~h}$, and the cell lysates were then analyzed for the aforementioned proteins. The results were representative of those

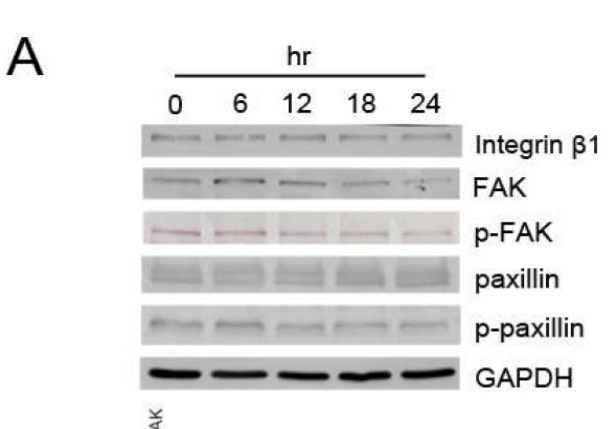

这.
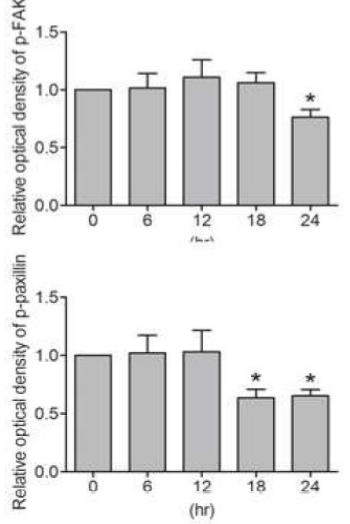

C
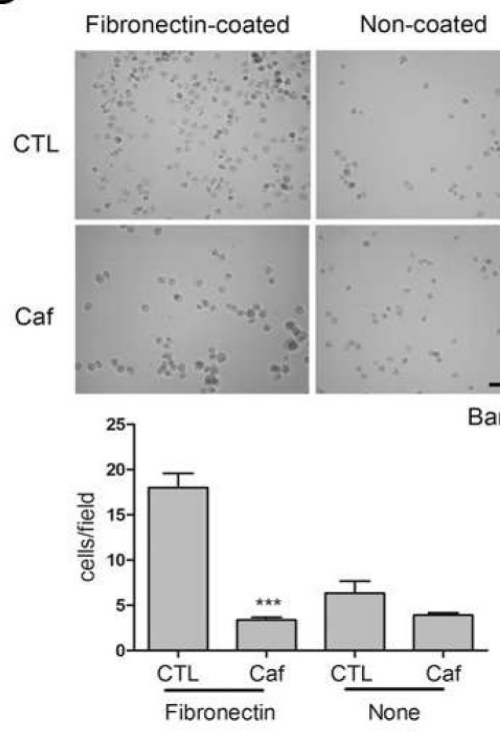
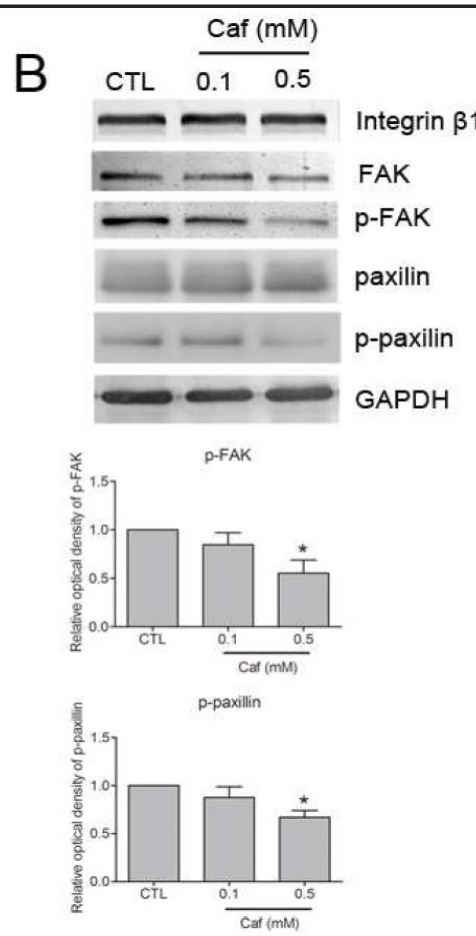

D

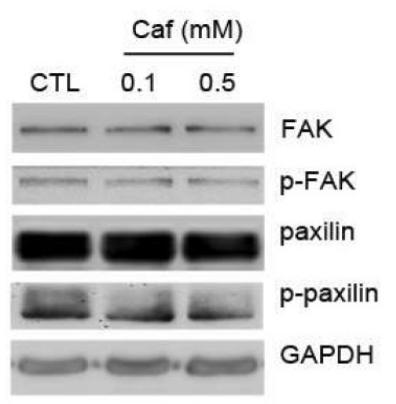

obtained in five experiments. GAPDH was used as the loading control. The lower panels show quantitative analyses of the levels of the aforementioned proteins $(\mathrm{n}=5) ;{ }^{*} p<0.05$ compared to the control group. (C) The adhesion ability of human U87MG glioma cells was assayed. After $24 \mathrm{hr}$ of treatment with $\mathrm{H}_{2} \mathrm{O}$ or $0.5 \mathrm{mM}$ caffeine, cells were detached from the culture dish and replated on fibronectin-coated or non-coated dishes for $15 \mathrm{~min} .{ }^{* * *} p<0.001$ compared fibronectin-coated control group after $24 \mathrm{~h}$. (D) Cell lysates were analyzed for FAK, p-FAK, paxillin, and p-paxillin using western blotting in U87MG glioma cells after caffeine treatment in fibronectin-coated dishes for 24 h. ${ }^{*} p<0.05$ when compared to the control group.

the survival rate of C6 glioma cells to 70\%. To avoid any effects on cell viability, doses of 0.5 $\mathrm{mM}$ caffeine were used throughout this study.

The effect of caffeine on glioma cell migration was investigated using Transwell migration and wound healing assays. The migration of C6 glioma cells was significantly 
Fig. 3. Effects of caffeine on the distributions of FAK and stress fibers in C6 glioma cells. After $24 \mathrm{~h}$ treatment, cells were immunostained with FAK (A, B) and counter stained with TRITC-phalloidin (C, D) and DAPI (E, F). Graph $\mathrm{G}$ and $\mathrm{H}$ are merged images. Bar $=20 \mu \mathrm{M}$.

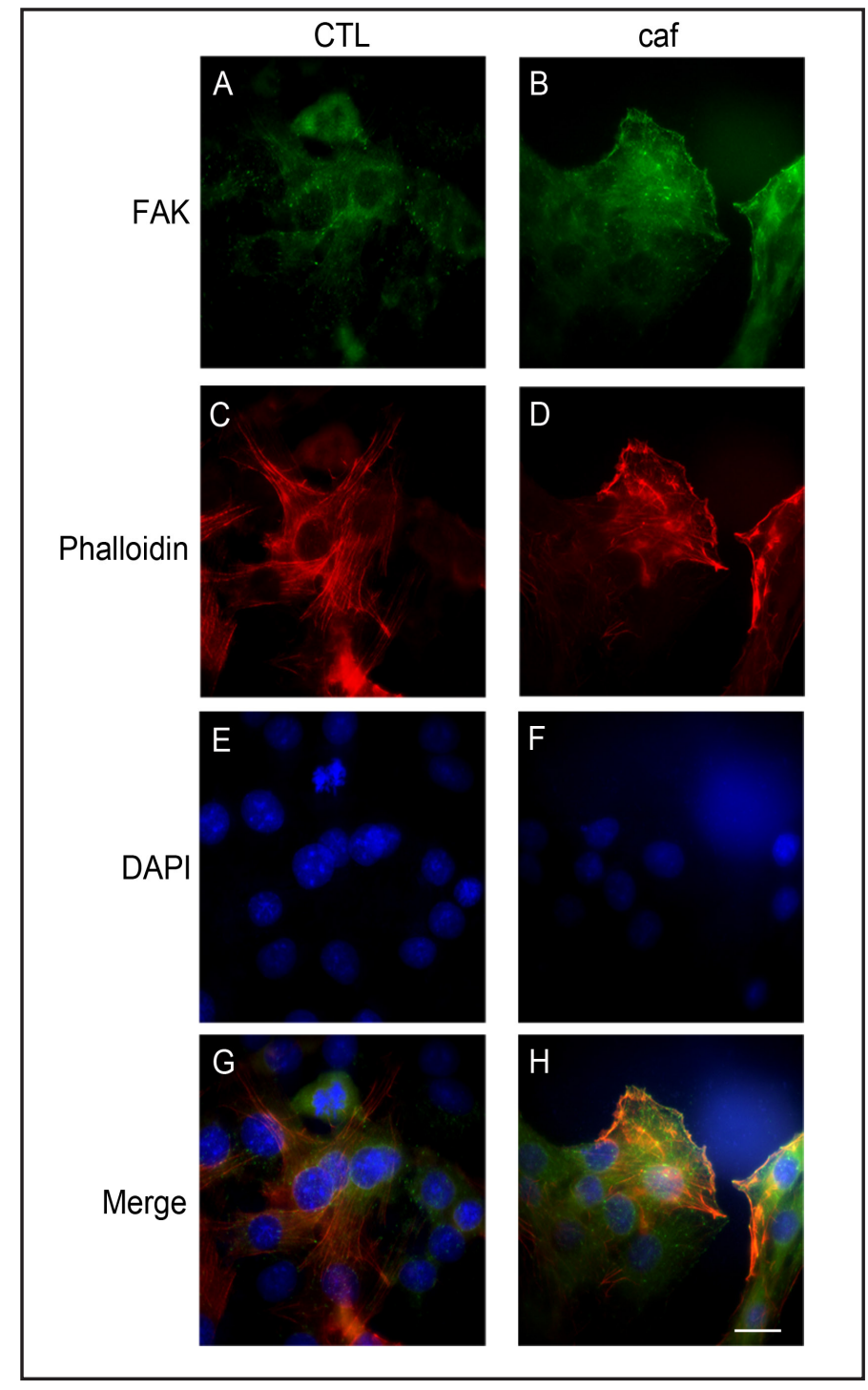

reduced after treatment with 0.5 or $1 \mathrm{mM}$ caffeine for $24 \mathrm{~h}$ (Fig. 1C). Although C6 glioma cell survival is more sensitive to caffeine than U87MG cell survival, treatment with 0.1 and $0.5 \mathrm{mM}$ caffeine reduced U87MG glioma cell migration (Fig. 1C). The results of the wound healing assay indicated that the wound area of the control group was larger than that of the caffeine group after $24 \mathrm{~h}$ both in C6 and U87MG glioma cells (Fig. 1D). These results indicated that caffeine decreased glioma cell migration.

\section{Caffeine reduced the phosphorylation of focal adhesion proteins and cell adhesion}

Focal adhesion proteins were studied in glioma cells after treatment with caffeine. A time-course study revealed that p-FAK and p-paxillin levels were decreased in C6 cells after $24 \mathrm{~h}$ of treatment with caffeine (Fig. 2A). Caffeine also led to downregulation of p-FAK and p-paxillin in U87MG cells (Fig. 2B). Cell adhesion ability was tested using fibronectin-coated dishes after caffeine treatment. Caffeine reduced the adhesion ability of glioma cells when replated on dishes coated with fibronectin (Fig. 2C). Furthermore, caffeine decreased p-FAK and p-paxillin on fibronectin-coated dishes (Fig. 2D). These results indicated that caffeine decreased activity of the focal adhesion complex, which contributed to the reduction in the adhesion ability of glioma cells.

Immunostaining was performed to observe the distribution of FAK and actin stress fibers. In the control group, FAKs were detected as puncta at the cell edge and ventral 
Fig. 4. Effect of caffeine on the phosphorylation of MLC. (A) C6 glioma cells were treated for different time intervals, and cell lysates were collected and analyzed for levels of phosphorylated MLC (p-MLC), MLC, $\beta$-actin and GAPDH (internal control). (B) U87MG glioma cells were treated with $0.5 \mathrm{mM}$ cell lysates were collected and analyzed for phosphorylated MLC (p-MLC), MLC and GAPDH (internal control). (C) Cells were treated with Y27632 $(10 \mu \mathrm{M})$ and ML-7 $(2 \mu \mathrm{M})$ for $1 \mathrm{~h}$ before and during incubation with $0.5 \mathrm{mM}$ caffeine for 24 hours, after which cell homogenates were analyzed for p-MLC. $* p<0.05 \quad$ compared to the control group; ${ }^{\#} p<0.05$ compared to the caffeine-treated group. caffeine for $24 \mathrm{~h}$, and

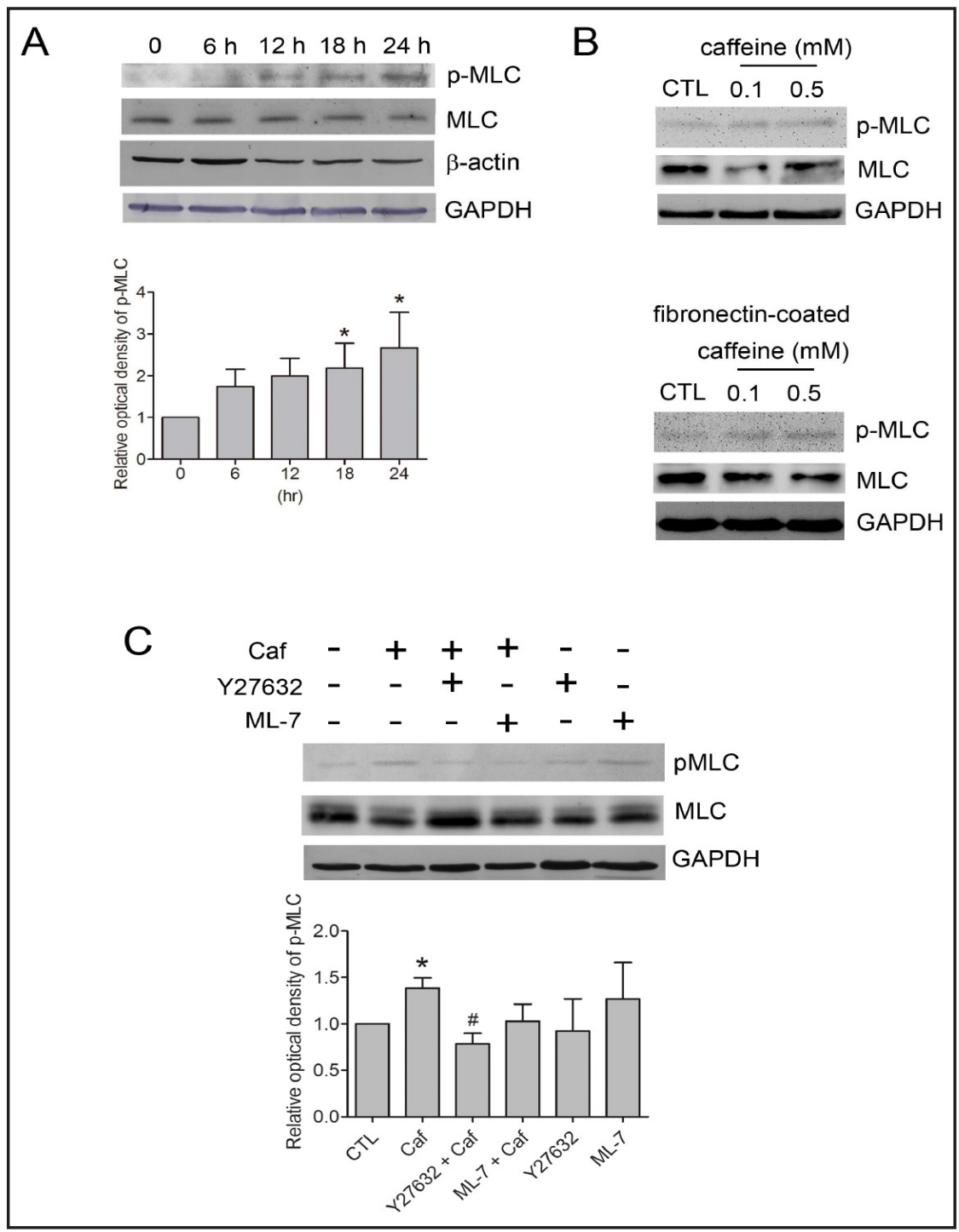

adhesion site (Fig. 3A). After caffeine treatment, the FAK distribution and the structure of stress fibers were impaired and accumulated at the cell edges, which was disadvantageous for cell migration (Fig. 3B and 3D). Moreover, few micronuclei (MN) were observed after caffeine treatment (Fig. 3F), which is a consequence of the conversion of TOPOII/DNA complexes to permanent DNA damage [16].

\section{Caffeine regulated cell migration through rock-fak cascade}

The phosphorylation of MLC, a substrate for both ROCK and MLCK [12], was two times higher than the level of the control group after caffeine treatment in non-coated dishes and fibronectin-coated dishes (Fig. 4A and 4B). As a result, a ROCK inhibitor, Y27632, and MLCK inhibitor, ML-7, were chosen to confirm the upstream activation of MLC by caffeine. Only Y27632 significantly prevented caffeine-induced MLC phosphorylation (Fig. 4C), suggesting that caffeine caused MLC phosphorylation via ROCK activation. Moreover, Y27632 blocked caffeine-reduced FAK and paxillin phosphorylation in C6 and U87MG glioma cells (Fig. 5). Although ML-7 inhibited the reduction of paxillin phosphorylation caused by caffeine in C6 glioma cells, only Y27632 prevented caffeine-decreased cell migration in C6 glioma cells (Fig. 6A) and U87MG glioma cells (Fig. 6B). Taken together, these results suggest that caffeine attenuated the phosphorylation of focal adhesion proteins and migration through ROCK in glioma cells. 
Fig. 5. Caffeine reduced the activity of focal adhesion proteins by ROCK. Cells were treated with Y27632 or ML-7 were pre-treated for $1 \mathrm{~h}$ before and during, $24 \mathrm{~h}$ incubation with $0.5 \mathrm{mM}$ caffeine, and then the cell homogenates were analyzed for p-FAK and p-paxillin in C6 (A) and U87MG (B) glioma cells (GAPDH as internal control). ${ }^{*} p<0.05$ compared to the control group; $\quad{ }^{*} p<0.05$ compared to the caffeine-treated group.

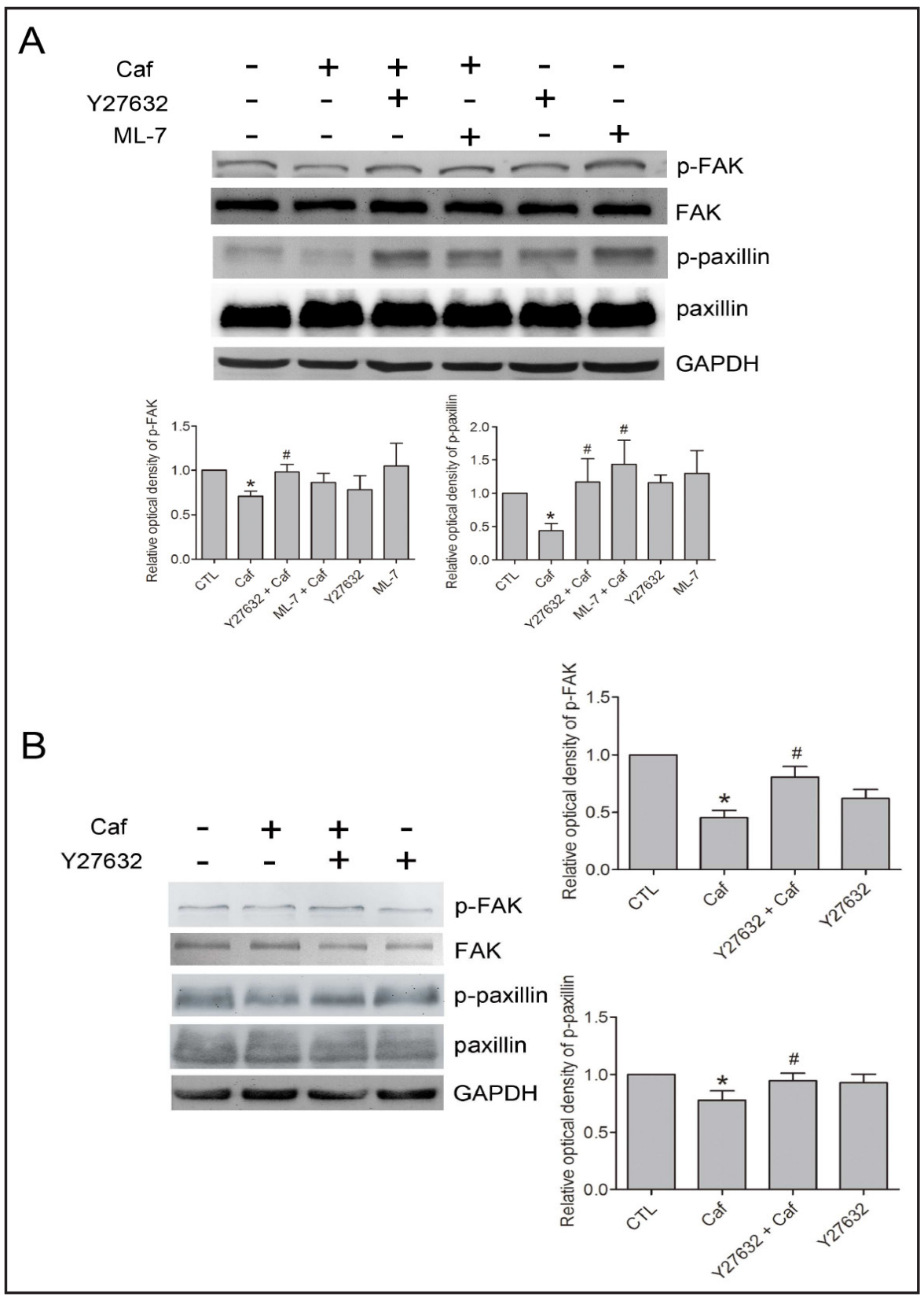

\section{Discussion}

Although caffeine has been reported to reduce cell migration and invasion, the mechanism responsible for these effects remains unclear [7, 17]. Caffeine alters IP3R and subsequently, intracellular calcium levels, which reduce migration and invasion in human glioma cells [7]. In non-glioma cells, caffeine decreases invasion of human leukemia U937 cells through the $\mathrm{Ca}^{2+} / \mathrm{ROS}$-mediated suppression of ERK/c-fos and activation of p38 MAPK/ c-jun pathways [17]. Furthermore, caffeine inhibits the motility of extra-villous trophoblasts by blocking the mammalian target of rapamycin complex 2 and Akt [18]. Here, caffeine treatment impairs focal adhesion protein activity that is blocked by ROCK activation, which leads to the down-regulation of both adhesion ability and migration in glioma cells.

The Rho-family pathway and calcium signaling are two basic systems that regulate the cytoskeleton and cell motility [19]. ROCK inhibition leads to Rac1 activation, which results in increased migration and invasion in human glioma cells [20]. Treatment with 
Fig. 6. Caffeine reduced cell migration by ROCK. C6 (A) and U87MG (B) glioma cells were treated with Y27632 or ML-7 for $1 \mathrm{~h}$ before and during incubation with $0.5 \mathrm{mM}$ caffeine for $24 \mathrm{~h}$, and then analyzed for cell migration. $\quad * p<0.05$, ${ }^{* *} p<0.01$ or $* * *$ $p<0.001 \quad$ compared to the control group; ${ }^{\#} p<0.05$, ${ }^{\# \#} p<0.01$ or $\quad \# \# p<0.001$ compared to the caffeine-treated group; ${ }^{+++} p<0.001$ compared to the Y27632+caffeine-treated group.

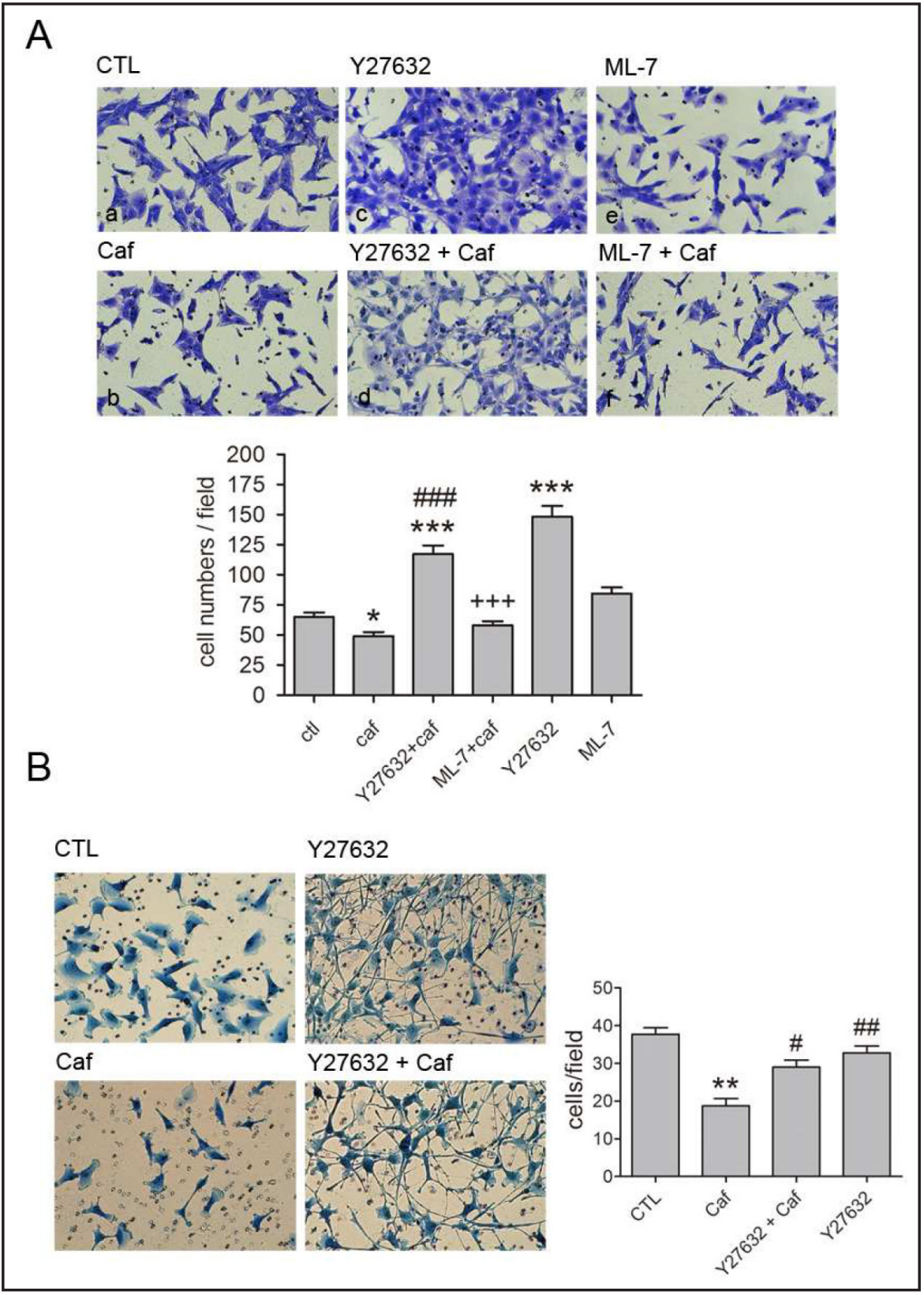

Y27632 resulted in a two-fold increase in cell migration in glioma cells. Moreover, ROCK activation causes a shift from filamentous to monomeric actin, leading to the disappearance of stress fibers in human U87MG glioma cells [13]. In the present study, caffeine induced MLC phosphorylation and stress fiber disassembly, indicating the involvement of ROCK in caffeine's effects on glioma cells.

Caffeine has been reported to increase MN formation in mouse bone marrow cells, while also reducing the number of MN induced by an antineoplastic drug, methotrexate [21]. Caffeine leads to MN formation in human lymphocytes, which is related to apoptosis and necrosis [22]. However, Alves et al. note that there is no correlation between MN formation and cell viability [23]. As shown in the present study, although few MN were observed after caffeine treatment, there was no difference in cell viability between the control-group and caffeine-treated group.

ROCK has been correlated with protein phosphatases as subsequently facilitating downstream signaling pathway. Phosphatase and tensin homolog (PTEN), a substrate 
of ROCK, dephosphorylates FAK and paxillin and contributes to the regulation of cell migration in mouse pre-osteoblast MC3T3-E1 cells [24]. Moreover, the ROCK signaling pathway coordinates protein phosphatase 1 (PP1) with cofilin activity to regulate skeletal dynamics in enteric neural crest cells [25]. However, both C6 and U87 glioma cells lack PTEN expression [15, 26]. Therefore, the role that regulation of phosphatases by ROCK plays in controlling FAK and paxillin phosphorylation after glioma cells are treated in caffeine warrants further investigation.

Intake of caffeine is estimated to be 200 $250 \mathrm{mg} /$ person per day in the USA [27], and $260 \mathrm{mg} /$ person per day in Japan [28]. The dose used in this study (10-4 $\mathrm{M}$ in U87MG cells) corresponds to an intake of $250 \mathrm{mg}$ caffeine, or 2-3 cups of coffee by a $70 \mathrm{~kg}$ human $[29,30]$. Hence, the concentrations of caffeine applied in this study are physiologically relevant.

\section{Conclusions}

Caffeine reduces the adhesion and migration of glioma cells by impairing the focal adhesion complex through ROCK (Fig. 7). In the future, caffeine may be helpful as part of adjunct therapy for glioma in addition to surgery, chemotherapy, and radiotherapy.

\section{Acknowledgements}

Contract grant sponsor: MAB-102-89

\section{Disclosure Statement}

The authors report no conflicts of interest.

\section{References}

1 Gritsenko PG, Ilina O, Friedl P: Interstitial guidance of cancer invasion. J Pathol 2012;226:185-199.

$\checkmark 2$ Louis DN, Ohgaki H, Wiestler OD, Cavenee WK, Burger PC, Jouvet A, Scheithauer BW, Kleihues P: The 2007 WHO classification of tumours of the central nervous system. Acta Neuropathol 2007;114:97-109.

-3 Holick CN, Smith SG, Giovannucci E, Michaud DS: Coffee, tea, caffeine intake, and risk of adult glioma in three prospective cohort studies. Cancer Epidemiol Biomarkers Prev 2010;19:39-47.

- 4 Tanaka H, Mizojiri K: Drug-protein binding and blood-brain barrier permeability. J Pharmacol ExpTherap 1999;288:912-918.

-5 5Ku BM, Lee YK, Jeong JY, Ryu J, Choi J, Kim JS, Cho YW, Roh GS, Kim HJ, Cho GJ, Choi WS, Kang SS: Caffeine inhibits cell proliferation and regulates PKA/GSK3beta pathways in U87MG human glioma cells. Mol Cells 2011;31:275-279.

-6 Sinn B, Tallen G, Schroeder G, Grassl B, Schulze J, Budach V, Tinhofer I: Caffeine confers radiosensitization of PTEN-deficient malignant glioma cells by enhancing ionizing radiation-induced G1 arrest and negatively regulating Akt phosphorylation. Mol Cancer Therap 2010;9:480-488.

-7 Kang SS, Han KS, Ku BM, Lee YK, Hong J, Shin HY, Almonte AG, Woo DH, Brat DJ, Hwang EM, Yoo SH, Chung CK, Park SH, Paek SH, Roh EJ, Lee SJ, Park JY, Traynelis SF, Lee CJ: Caffeine-mediated inhibition of calcium release channel inositol 1,4,5-trisphosphate receptor subtype 3 blocks glioblastoma invasion and extends survival. Cancer Res 2010;70:1173-1183. 
8 Zhao J, Guan JL: Signal transduction by focal adhesion kinase in cancer. Cancer Metastasis Rev 2009;28:3549.

-9 Piao Y, Lu L, de Groot J: AMPA receptors promote perivascular glioma invasion via beta1 integrindependent adhesion to the extracellular matrix. Neuro Oncol 2009;11:260-273.

10 Natarajan M, Hecker TP, Gladson CL: FAK signaling in anaplastic astrocytoma and glioblastoma tumors. Cancer J 2003;9:126-133.

11 Platten M, Wick W, Wild-Bode C, Aulwurm S, Dichgans J, Weller M: Transforming growth factors beta(1) (TGF-beta(1)) and TGF-beta(2) promote glioma cell migration via Up-regulation of alpha(V)beta(3) integrin expression. Biochem Biophys Res Commun 2000;268:607-611.

-12 Totsukawa G, Wu Y, Sasaki Y, Hartshorne DJ, Yamakita Y, Yamashiro S, Matsumura F: Distinct roles of MLCK and ROCK in the regulation of membrane protrusions and focal adhesion dynamics during cell migration of fibroblasts. J Cell Biol 2004;164:427-439.

13 Caraballo-Miralles V, Cardona-Rossinyol A, Garcera A, Villalonga P, Soler RM, Olmos G, Llado J: SMN deficiency attenuates migration of U87MG astroglioma cells through the activation of RhoA. Mol Cell Neurosci 2012;49:282-289.

14 de Amicis F, Lanzino M, Kisslinger A, Cali G, Chieffi P, Ando S, Mancini FP, Tramontano D: Loss of prolinerich tyrosine kinase 2 function induces spreading and motility of epithelial prostate cells. J Cell Physiol 2006;209:74-80.

15 Sullivan R, Burnham M, Torok K, Koffer A: Calmodulin regulates the disassembly of cortical F-actin in mast cells but is not required for secretion. Cell Calcium 2000;28:33-46.

-16 Benadiba M, Miyake JA, Colquhoun A: Gamma-linolenic acid alters Ku80, E2F1, and bax expression and induces micronucleus formation in C6 glioma cells in vitro. IUBMB Life 2009;61:244-251.

17 Liu WH, Chang LS: Caffeine induces matrix metalloproteinase-2 (MMP-2) and MMP-9 down-regulation in human leukemia U937 cells via $\mathrm{Ca}^{2+} /$ ROS-mediated suppression of ERK/c-fos pathway and activation of p38 MAPK/c-jun pathway. J Cell Physiol 2010;224:775-785.

18 Grant I, Cartwright JE, Lumicisi B, Wallace AE, Whitley GS: Caffeine inhibits EGF-stimulated trophoblast cell motility through the inhibition of mTORC2 and Akt. Endocrinology 2012;153:4502-4510.

19 Klopocka W, Korczynski J, Pomorski P: Cytoskeleton and nucleotide signaling in glioma C6 cells. Adv Exp Med Biol 2013;986:103-119.

20 Salhia B, Rutten F, Nakada M, Beaudry C, Berens M, Kwan A, Rutka JT: Inhibition of Rho-kinase affects astrocytoma morphology, motility, and invasion through activation of Rac1. Cancer Res 2005;65:87928800.

21 Choudhury RC, Palo AK: Modulatory effects of caffeine on methotrexate-induced cytogenotoxicity in mouse bone marrow. Environ Toxicol Pharmacol 2004;15:79-85.

22 Wnuk M, Lewinska A, Oklejewicz B, Bugno M, Slota E, Bartosz G: Evaluation of the cyto- and genotoxic activity of yerba mate (Ilex paraguariensis) in human lymphocytes in vitro. Mutation Res 2009;679:18-23. Alves RJV, Jotz GP, do Amaral VS, Montes TMH, Menezes HS, de Andrade HHR: The evaluation of mate (Ilex paraguariensis) genetic toxicity in human lymphocytes by the cytokinesis-block in the micronucleus assay. Toxicology in Vitro 2008;22:695-698.

24 Yang S, Kim HM: The RhoA-ROCK-PTEN pathway as a molecular switch for anchorage dependent cell behavior. Biomaterials 2012;33:2902-2915.

25 Zhang Y, Kim TH, Niswander L: Phactr4 regulates directional migration of enteric neural crest through PP1, integrin signaling, and cofilin activity. Genes Dev 2012;26:69-81.

26 Kubiatowski T, Jang T, Lachyankar MB, Salmonsen R, Nabi RR, Quesenberry PJ, Litofsky NS, Ross AH, Recht LD: Association of increased phosphatidylinositol 3-kinase signaling with increased invasiveness and gelatinase activity in malignant gliomas. J Neurosurg 2001;95:480-488.

27 Mandel HG: Update on caffeine consumption, disposition and action. Food Chem Toxicol 2002;40:12311234.

28 Yamada M, Sasaki S, Murakami K, Takahashi Y, Okubo H, Hirota N, Notsu A, Todoriki H, Miura A, Fukui M, Date C: Estimation of caffeine intake in Japanese adults using $16 \mathrm{~d}$ weighed diet records based on a food composition database newly developed for Japanese populations. Public Health Nutr 2010;13:663-672.

-29 Varani K, Portaluppi F, Gessi S, Merighi S, Vincenzi F, Cattabriga E, Dalpiaz A, Bortolotti F, Belardinelli L, Borea PA: Caffeine intake induces an alteration in human neutrophil A2A adenosine receptors. Cell Mol Life Sci 2005;62:2350-2358.

30 Sudano I, Binggeli C, Spieker L, Luscher TF, Ruschitzka F, Noll G, Corti R: Cardiovascular effects of coffee: is it a risk factor? Prog Cardiovasc Nurs 2005;20:65-69. 